\title{
Hyperbaric Oxygen Therapy in Interstitial Cystitis/Painful Bladder Syndrome
}

\author{
S. G. Parker ${ }^{1 \#}$, I. Miakhil², S. S. Kommu ${ }^{1}$ \\ ${ }^{1}$ Urology Department, The Princess Royal University Hospital, South London Healthcare NHS Foundation Trust, \\ Bromley, UK \\ ${ }^{2}$ Department of Urology, Peterborough City Hospital, Edith Cavell Campus, Peterborough, UK \\ Email: "samparker@nhs.net, iqmiakhil@gmail.com, sashurol@gmail.com
}

Received April 12, 2013; revised May 15, 2013; accepted May 22, 2013

Copyright (C) 2013 S.G. Parker et al. is an open access article distributed under the Creative Commons Attribution License, which permits unrestricted use, distribution, and reproduction in any medium, provided the original work is properly cited.

\begin{abstract}
Introduction: Hyperbaric oxygen therapy $(\mathrm{HBO})$ is emerging as an alternative technique for treating refractory interstitial cystitis (IC). The theory is that the increased dissolved oxygen in the blood raises the levels of oxygen in the tissues and improves tissue healing. Other urological disorders such as radiation cystitis, Fournier's gangrene and cyclophosphamide cystitis have also shown a good response to HBO therapy. Method: A literature search with the terms "interstitial cystitis", "painful bladder syndrome" and "hyperbaric oxygen therapy" found four papers that have trialed HBO therapy in IC patients; three case series and one randomized control trial. Results: A total of 31 patients have been treated with HBO therapy. All four studies show a symptomatic improvement in pain, urgency, bladder capacity and O'Leary-Sant interstitial cystitis index. Urinary frequency only improved in three out of four of the trials. The percentage of patients considered as responders to treatment varied at $25 \%, 66.7 \%, 82 \%$ and $100 \%$. Conclusion: Preliminary trials of HBO therapy seem to have a good patient response with effective symptomatic relief. The patient response rates varied greatly between the trials. This is due to each trial's different definition of a "patient responder". Further work in urology departments at $\mathrm{HBO}$ centers is required to further assess the benefits of $\mathrm{HBO}$ treatment in IC.
\end{abstract}

Keywords: Hyperbaric Oxygen Therapy; Interstitial Cystitis; Painful Bladder Syndrome

\section{Introduction}

Painful bladder syndrome (PBS)/interstitial cystitis (IC) is a disabling chronic condition defined as 'the complaint of suprapubic pain related to bladder filling, accompanied by other symptoms such as increased daytime and night-time frequency in the absence of proven urinary infection or other obvious pathology [1]. Reports of its prevalence vary widely from 7 cases per 100 women [2] to 18 cases per 100,000 [3]. The pathogenesis is multifactorial. The most popular theory is based on histamine release from mast cells, which have invaded the detrusor muscle and the surrounding structures (i.e. the blood vessels, nerves and lymphatics). Histamine causes pain, hyperaemia and fibrosis. Alternatively IC could be attributed to an abnormal glycosaminoglycan layer, which may allow urine to leak past the luminal surface, causing inflammation of the muscle layers. There are several oth-

\footnotetext{
*The authors of this paper have no actual or potential conflicts of interest in its publication.

${ }^{\#}$ Corresponding author.
}

er theories of pathogenesis. Numerous therapeutic approaches for IC have been tried. These can be divided into behavioral therapies, oral medications, intravesical drug instillations, nerve stimulation techniques and surgery. Hyperbaric oxygen therapy (HBO) is an emerging alternative therapy for patients who are resistant to conventional therapeutic techniques.

The principle behind HBO is to increase the dissolved oxygen in blood when it is administered at high pressure. Then increasing amounts of oxygen can be administered to tissues. Hyper-oxygenation of tissues has anti-inflammatory, analgesic effects and enhances the action of the lymphocytes and macrophages, phagocytosis facilitating and healing. These positive effects have been shown to improve healing in a number of urological disorders, including Fournier's gangrene, radical cystitis and cyclophosphamide cystitis [4]. In radiation cystitis the histological features include interstitial fibrosis and sub-mucosal haemorrhage, which correspond to the classical histological features of IC. Therefore it seems logical to try $\mathrm{HBO}$ in IC patients. Although further work is 
necessary to perform randomized control trials to assess the benefits of hyperbaric oxygen therapy [4]. In this paper we will analyze how effective HBO has been with IC Patients so far.

\section{Methods}

We carried out a literature search using the PubMed and the NHS library search engines. For our search we used the terms "interstitial cystitis", "painful bladder syndrome" and "hyperbaric oxygen therapy". The search results were restricted to human trials and could be published in any language.

Flow diagram for the literature search;

$$
\begin{aligned}
& \text { "Interstitial cystitis" } \\
& \text { "Painful bladder syndrome" } \\
& \text { "Hyperbaric oxygen therapy" } \\
& \downarrow \\
& \text { "NHS library search } \\
& \text { engine" } \\
& \text { "PubMed search engine" } \\
& \downarrow \\
& \text { Van Ophoven A. et al. } \\
& \text { (2004) [5] } \\
& \text { Tanaka T. et al. (2007) [6] } \\
& \text { Van Ophoven A. et al. } \\
& \text { (2007) [7] } \\
& \text { Tanaka T. et al. (2011) [8] }
\end{aligned}
$$

We selected papers that evaluated the use of HBO directly on interstitial cystitis.

\section{Results}

In total we found 4 papers; 1 randomized single-blind control trial; Van Ophoven A. et al., 2007 [7] and three case series; Tanaka T. et al., 2011 [8], Tanaka T. et al., 2007 [6] and Van Ophoven A. et al., 2004 [5]. A total of 40 patients were included. 7 of these patients were in the randomized control trial and received placebo treatment. 2 patients in the treatment group of the RCT didn't complete the course of HBO and could not be analyzed. In total 31 patients with IC have received HBO in the literature.

Eighteen of the patients treated with $\mathrm{HBO}$ received 90 mins/day of $100 \%$ oxygen at 2.4 ata 6 days a week for 5 weeks, (a total of 30 sessions). Eight patients received 60 $\mathrm{mins} /$ day of $100 \%$ oxygen at 2.0 ata 5 days a week for four weeks, (a total of 20 sessions) and 5 of the patients received $60 \mathrm{mins} /$ day of $100 \%$ oxygen at 2.0 ata 5 days a week for two weeks (a total of 10 sessions).

Table 1 shows a summary of the results from the four studies included. All of the studies show a symptomatic improvement in pain, urgency, bladder capacity and O'Leary-Sant interstitial cystitis symptoms index (ICSI). The three case series all show a reduction in the $24 \mathrm{~h}$ urinary frequency however the randomized control trial shows no reduction in $24 \mathrm{~h}$ urinary frequency.

The percentage of patients who responded to treatment varied greatly between the four studies. $25 \%$ [7] of treated patients from the randomized control trial were considered as responders, where as the case series show patient response rates of $66.7 \%$ [5], 82\% [8] and $100 \%$ [6].

Adverse effects from HBO were well documented. Each study had one patient who suffered from mild Eustachian tube dysfunction. Three patients acquired otitis media. Two patients had to have oral medication for temporary claustrophobia and one patient had to have oral medication for a rise in blood pressure.

\section{Discussion}

There is noticeable variation in response rates to HBO in these studies. This is due to the different classifications used by authors to differentiate between a patient responder and non-responder. In further studies there needs to be a standard classification that defines whether or not a patient responds to $\mathrm{HBO}$.

These studies do show encouraging results. Patients do seem to get symptomatic relief from HBO. Larger studies are required to further investigate the efficacy of $\mathrm{HBO}$ in patients with IC. These studies should include patient demographics, bladder biopsies, intra-vesical imaging and possibly patient $\mathrm{CT}$ scanning. This data can then be used to accurately predict the type of patient that is likely to respond to HBO. As HBO is a limited and costly resource, its unnecessary use should be avoided. In the most recent study Tanaka 2011 the patients received cystoscopy and hydro-distension before the HBO therapy. During cystoscopy the bladder mucosa was inspected for mucosal ulcerations (Hunner's ulcer). Eight out of the 11 patients were found to have ulcerative IC and 7 of these 8 were treatment responders. None of the non-ulcerative IC patients responded the HBO therapy. There seems to be a strong correlation between an ulcerative IC bladder mucosa and a response to HBO therapy.

There doesn't seem to be a connection between the number of HBO sessions and the beneficial therapeutic effect experienced by patients. Two studies Van Ophoven A. et al. (2007) [7] and Van Ophoven A. et al. (2004) [5] used hyperbaric oxygen at a higher pressure and for longer duration than the other two (Tanaka T. et al., 2011) [8], (Tanaka T. et al., 2007) [6] and the patient outcomes are no different between these two groups of studies.

There does, however, seem to be some benefit from increased dosages of HBO therapy amongst the treatment 
Table 1. Summarizing the results from all the four papers trialing hyperbaric oxygen therapy for interstitial cystitis.

\begin{tabular}{|c|c|c|c|c|c|}
\hline & Tanaka (2007) & Tanaka (2011) & Ophoven (2004) & Ophoven (2006) & $\begin{array}{c}\text { Total } \\
\text { patients }\end{array}$ \\
\hline Type of study & Case series & Case series & Case series & Randomized control trial & \\
\hline No. of patients & 2 & 11 & 6 & 21 & 40 \\
\hline $\begin{array}{l}\text { No. of patients } \\
\text { treated }\end{array}$ & 2 & 11 & 6 & 14 & 33 \\
\hline $\begin{array}{l}\text { No. finishing } \\
\text { treatment }\end{array}$ & 2 & 11 & 6 & 12 & 31 \\
\hline $\begin{array}{l}\text { Definition of } \\
\text { responder }\end{array}$ & $\begin{array}{l}\text { Improvement of } \\
\text { symptoms }\end{array}$ & $\begin{array}{l}\text { Significant improvement in } \\
\text { symptoms }(\mathrm{p}<0.05)\end{array}$ & $\begin{array}{l}\text { Satisfaction with } \\
\text { outcome-Good or } \\
\text { Excellent }\end{array}$ & $\begin{array}{c}\text { Global response } \\
\text { assessment scale } \geq \\
\text { moderately improved }\end{array}$ & \\
\hline $\begin{array}{c}\text { No. of responders } \\
\text { to treatment } \\
\text { Outcomes } \\
\text { measured; }\end{array}$ & $2(100 \%)$ & $7(82 \%)$ & $4(66.7 \%)$ & $3(25 \%)$ & 16 \\
\hline ICSI score & - & $\mathrm{y}$ & $\mathrm{y}$ & $\mathrm{y}$ & \\
\hline Bladder capacity & $\mathrm{y}$ & $\mathrm{y}$ & $\mathrm{y}$ & $\mathrm{y}$ & \\
\hline Pain (VAS) & $\mathrm{y}$ & $\mathrm{y}$ & $\mathrm{y}$ & $\mathrm{y}$ & \\
\hline Urgency (VAS) & - & $\mathrm{y}$ & $\mathrm{y}$ & $\mathrm{y}$ & \\
\hline \multirow[t]{2}{*}{$24 \mathrm{~h}$ frequency } & $\mathrm{y}$ & $\mathrm{y}$ & $\mathrm{y}$ & $\mathrm{y}$ & \\
\hline & Tanaka (2007) & Tanaka (2011) & Ophoven (2004) & Ophoven (2006) & \\
\hline $\begin{array}{l}\text { No. of patients } \\
\text { treated }\end{array}$ & 2 & 11 & 6 & 14 & \\
\hline \multicolumn{6}{|c|}{ When outcomes measured; } \\
\hline post treatment & & $\mathrm{y}$ & $\mathrm{y}$ & $\mathrm{y}$ & \\
\hline $1 \mathrm{mo}$ & $\mathrm{y}$ & $\mathrm{y}$ & - & $\mathrm{y}$ & \\
\hline $3 \mathrm{mo}$ & $\mathrm{y}$ & $\mathrm{y}$ & $\mathrm{y}$ & $\mathrm{y}$ & \\
\hline $6 \mathrm{mo}$ & $\mathrm{y}$ & $\mathrm{y}$ & $\mathrm{y}$ & $\mathrm{y}$ & \\
\hline $\begin{array}{l}\text { No. of patients } \\
\text { treated }\end{array}$ & 2 & 11 & 6 & 14 & \\
\hline \multirow[t]{7}{*}{ HBO treatment } & 2.0 ata $100 \%$ oxygen & 2.0 ata $100 \%$ oxygen & 2.4 ata $100 \%$ oxygen & 2.4 ata $100 \%$ oxygen & \\
\hline & $60 \mathrm{mins} /$ day & $60 \mathrm{mins} /$ day & $90 \mathrm{mins} /$ day & $90 \mathrm{mins} /$ day & \\
\hline & 5 days/week & 5 days/week & 5 weeks & 5 weeks & \\
\hline & 4 weeks & 8 patients- 2 weeks (10 sessions) & 6 days/week & 6 days/week & \\
\hline & 20 sessions & 3 patients- 4 weeks (20 sessions & 30 sessions & 30 sessions & \\
\hline & Tanaka (2007) & Tanaka $(2011)$ & Ophoven (2004) & Ophoven (2006) & \\
\hline & & $\begin{array}{c}\text { (mean results for the } 7 \text { responders in } \\
\text { brackets) }\end{array}$ & & & \\
\hline $\begin{array}{l}\text { No. of patients } \\
\text { treated }\end{array}$ & 2 & 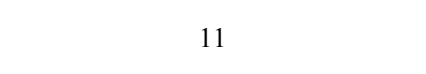 & 6 & 14 & 33 \\
\hline $\begin{array}{l}\text { No. of patients } \\
\text { finishing tx }\end{array}$ & 2 & 11 & 6 & 12 (2 pts dropped out) & 31 \\
\hline \multicolumn{6}{|l|}{ ICSI } \\
\hline Baseline & $\sim$ & $26.7 \pm 7.0(26)$ & $27.3 \pm 4.1$ & $25.7 \pm 5.7$ & \\
\hline 1 month & $\sim$ & $\sim(12)$ & $16.2 \pm 6.2$ & $20.6 \pm 7.8$ & \\
\hline 3 months & $\sim$ & $\sim(12)$ & $16.3 \pm 9.0$ & $19.9 \pm 7.9$ & \\
\hline 12 months & $\sim$ & $18.7 \pm 7.4(22.5)$ & $9.75 \pm 5.7$ (4 responders) & $\sim$ & \\
\hline \multicolumn{6}{|l|}{$\begin{array}{l}\text { Bladder capacity } \\
\qquad(\mathrm{mL})\end{array}$} \\
\hline Baseline & $55 \pm 35.4$ & $\sim(62)$ & $106.33 \pm 40.5$ & $127 \pm 55$ & \\
\hline 1 month & $140 \pm 14.1$ & $\sim(150)$ & $155.16 \pm 21.8$ & $139 \pm 61$ & \\
\hline
\end{tabular}




\begin{tabular}{|c|c|c|c|c|c|}
\hline \multicolumn{6}{|l|}{ Continued } \\
\hline 3 months & $144 \pm 33.9$ & $\sim(200)$ & $149.66 \pm 24.1$ & $147 \pm 49$ & \\
\hline 12 months & $\sim$ & $\sim(100)$ & $189 \pm 19.4$ (4 responders) & $\sim$ & \\
\hline \multicolumn{6}{|c|}{ Pain (VAS—100 mm scale) } \\
\hline Baseline & $85 \pm 21.2$ & ${ }^{*} 85.6 \pm 11.1(88.9)$ & $56.5 \pm 28.5$ & $43.1 \pm 20.5$ & \\
\hline 1 month & $30 \pm 0.0$ & ${ }^{*} \sim(22.2)$ & $27.66 \pm 27.9$ & $33.9 \pm 22.1$ & \\
\hline 3 months & $32.5 \pm 3.5$ & ${ }^{*} \sim(22.2)$ & $26 \pm 31.1$ & $31.2 \pm 19.8$ & \\
\hline 12 months & $\sim$ & ${ }^{*} 37.8 \pm 27.8(33.3)$ & $15.25 \pm 12.1$ (4 responders) & $\sim$ & \\
\hline \multicolumn{6}{|c|}{ Urgency (VAS-100 mm scale) } \\
\hline Baseline & $\sim$ & ${ }^{*} 73.3 \pm 9.9(77.7)$ & $73.33 \pm 16.3$ & $60.2 \pm 15.0$ & \\
\hline 1 month & $\sim$ & ${ }^{*} \sim(22.2)$ & $45.16 \pm 20.4$ & $48.6 \pm 23.4$ & \\
\hline 3 months & $\sim$ & ${ }^{*} \sim(33.3)$ & $43.83 \pm 31.2$ & $49.9 \pm 35.2$ & \\
\hline 12 months & $\sim$ & ${ }^{*} 47.8 \pm 26.7(27.7)$ & $23.25 \pm 15.8$ (4 responders) & $\sim$ & \\
\hline \multicolumn{6}{|l|}{$24 \mathrm{~h}$ frequency } \\
\hline Baseline & $23 \pm 2.8$ & $22.4 \pm 4.0(24)$ & $19.5 \pm 4.7$ & $16.2 \pm 5.1$ & \\
\hline 1 month & $10 \pm 2.8$ & $\sim(10)$ & $14 \pm 5.0$ & $17.5 \pm 6.3$ & \\
\hline 3 months & $9.5 \pm 0.7$ & $\sim(10)$ & $14.83 \pm 8.1$ & $15.9 \pm 7.0$ & \\
\hline 12 months & - & $14.6 \pm 2.0(15)$ & $8.74 \pm 2.2(4$ responders $)$ & - & \\
\hline \multirow[t]{4}{*}{ Adverse effects } & $\begin{array}{l}\text { Eustachian tube } \\
\text { dysfunction }\end{array}$ & Eustachian tube dysfunction & $\begin{array}{l}\text { Eustachian tube } \\
\text { dysfunction }\end{array}$ & $\begin{array}{l}\text { Eustachian tube } \\
\text { dysfunction }\end{array}$ & $\begin{array}{l}\text { Prevalence } \\
4 / 31(13 \%)\end{array}$ \\
\hline & & Otitis Media x 3 & & & $3 / 31(9.7 \%)$ \\
\hline & & & Temporary claustrophobia & Temporary claustrophia & $2 / 31(6.5 \%)$ \\
\hline & & & Mild arterial hypertension & & $1 / 31(3.2 \%)$ \\
\hline
\end{tabular}

"Figures converted from a VAS scale of 0 to 9 to a scale of 0 to 100 to make comparison of parameters between studies easier.

Table 2. Showing that increased HBO therapy in the Ophoven 2004 paper produces better symptomatic results with patient responders at 12 months post therapy.

\begin{tabular}{ccc}
\hline $\begin{array}{c}\text { Symptom parameters of “patient } \\
\text { responders" at 12 months }\end{array}$ & Tanaka 2011 patient responders (n= 7) & Ophoven 2004 patient responders (n = 4) \\
\hline ICSI score & 22.5 & 9.75 \\
Bladder capacity & $100 \mathrm{~cm}^{3}$ & $189 \mathrm{~cm}^{3}$ \\
Pain (VAS 100 ml) & 33.3 & 15.25 \\
Urgency (VAS 100 ml) & 27.7 & 23.25 \\
24 h frequency & 15 & 8.74 \\
\hline
\end{tabular}

responders. At 12 months follow up four treatment responders from the Ophoven case series had a mean ICSI, mean bladder capacity, mean pain score, mean urgency score and $24 \mathrm{~h}$ frequency of $9.75,189 \mathrm{~cm}^{3}, 15.25,23.25$ and 8.74 respectively; much improved from the baseline values. This is considerably better than the corresponding values of $22.5,100 \mathrm{~cm}^{3}, 33.3,27.7$ and 15 in the responders from the Tanaka T. et al., 2011 [8] case series; see Table 2.

This could imply that HBO therapy at higher doses does have extra therapeutic benefits amongst treatment responders. However, as mentioned above, a proper definition of a "patient responder" is required before accurate comparisons between studies can be made.

There are practical issues involved with hyperbaric oxygen therapy administration. Hospitals that have a HBO therapy center are few and far between. There is a high demand for elective HBO therapy and whilst treatment of interstitial cystitis remains theoretical, patient access to HBO therapy will be difficult. In addition for HBO therapy to be used regularly its costs must also be considered. Its use has been estimated at a cost of $£ 208$ per treatment session [9]. For these reasons potential treatment responders must be identified so that HBO therapy is not wasted on treating non-responders and there is no unnecessary financial investment.

\section{Conclusion}

Preliminary trials of HBO therapy seem to have a good patient response with effective symptomatic relief. The patient response rates varied greatly between the trials. 
This is due to each trial's different definition of a "patient responder". Further work in urology departments that have access to nearby HBO therapy is required to further assess its therapeutic affects.

\section{REFERENCES}

[1] P. Abrams, et al., "The Standardization of Terminology of Lower Urinary Tract Function: Report from the Standardization Sub-Committee of the International Continence Society," Neurourology and Urodynamics, Vol. 21, No. 2, 2002, pp. 167-178. doi:10.1002/nau.10052

[2] J. Neuhaus and T. Schwalenberg, "Intravesical Treatments of Bladder Pain Syndrome/Interstitial Cystitis," Nature Reviews Urology, Vol. 9, No. 12, 2012, pp. 707720.

[3] K. J. Oravisto, "Epidemiology of Interstitial Cystitis," Annales Chirurgiae et Gynaecologiae Fenniae, Vol. 64, No. 2, 1975, pp. 75-77.

[4] D. G. Vilar, et al., "Hyperbaric Oxygen Treatment in Urology," Archivos Españoles de Urología, Vol. 64, No. 6, 2011, pp. 507-516.
[5] A. Van Ophoven, et al., "Hyperbaric Oxygen for the Treatment of Interstitial Cystitis: Long-Term Results of a Prospective Pilot Study," European Urology, Vol. 46, No. 1, 2004, pp. 108-113. doi:10.1016/j.eururo.2004.03.002

[6] T. Tanaka, et al., "Oxygen Therapy for Interstitial Cystitis Resistant to Conventional Treatments," International Journal of Urology, Vol. 14, No. 6, 2007, pp. 563-565. doi:10.1111/j.1442-2042.2007.01599.x

[7] A. Van Ophoven, et al., "Safety and Efficacy of Hyperbaric Oxygen Therapy for the Treatment of Interstitial Cystitis: A Randomized, Sham Controlled, Double-Blind Trial," Journal of Urology, Vol. 176, No. 4, 2007, pp. 1442-1446. doi:10.1016/j.juro.2006.06.065

[8] T. Tanaka, et al., "Hyperbaric Oxygen Therapy for Painful Bladder Syndrome/Interstitial Cystitis Resistant to Conventional Treatments; Long Term Results of a Case Series in Japan," BMC Urology, Vol. 11, 2011, p. 11.

[9] D. Smart, et al., "A Cost-Analysis Case Study of Radiation Cystitis Treatment Including Hyperbaric Oxygen Therapy," Diving and Hyperbaric Medicine Journal, Vol. 42, No. 2, 2012, pp. 92-97. 